An Operational Integration of Lifespan Development Theories

\author{
Rachel S. Rauvola, Ph.D.* \\ DePaul University \\ Cort W. Rudolph, Ph.D. \\ Saint Louis University
}

Rachel S. Rauvola, Department of Psychology, DePaul University, Chicago, IL, USA. Cort W. Rudolph, Department of Psychology, Saint Louis University, St. Louis, MO, USA.

Correspondence concerning this article should be addressed to Rachel S. Rauvola, DePaul

University, Byrne Hall, Chicago, IL, 60614, rrauvola@ depaul.edu, +1(314) 537-9837

Please Cite As:

Rauvola, R. S., \& Rudolph, C. W. (2021). An operational integration of lifespan development theories. Current Psychology. [In Press Accepted Manuscript].

Availability of data, pre-registration, code, and materials: All data, code, and materials are available in an online appendix on OSF (https://osf.io/9t5za/). A masked pre-registration is available on OSF as well (https://osf.io/uwn3m). 


\begin{abstract}
Lifespan theories seek to explain the ways that individuals manage their development, staying healthy and content amidst age-related gains and losses. However, the lifespan literature is fragmented, with constructs studied separately rather than in concert. This study addresses these issues, generating evidence regarding the integrative factor structure and well-being implications of developmental self-regulation constructs. An age-diverse adult sample $(n=506)$ completed scales measuring constructs derived from four primary lifespan theories (dual-process model of assimilative and accommodative coping, motivational theory of life-span development, model of selection, optimization, and compensation, socioemotional selectivity theory), in addition to well-being and social desirability measures, at two time points. Pre-registered hypotheses were largely supported, with a bifactor structure observed, and significant, positive relationships found between the general developmental self-regulation factor (“ $D$ ”) and well-being. Lending further support, the same bifactor structure was replicated in a separate, hold out cross-sectional sample of age-diverse adults $(n=585)$.
\end{abstract}

Keywords: self-regulation, control, goals, well-being 


\section{An Operational Integration of Lifespan Development Theories}

Aging is often portrayed as loss-filled. However, there is evidence that aging can be an agentic and positive experience filled with gains that compensate for deficits. This has implications for theoretical and empirical aging conceptualizations, particularly for the metatheoretical lifespan perspective. Four dominant motivation theories comprise this perspective and prompt integration: the dual-process model of assimilative and accommodative coping (AAC; e.g., Brandtstädter \& Renner, 1990), the motivational theory of lifespan development (MTLD; e.g., Heckhausen et al., 2010), the model of selection, optimization, and compensation (SOC; e.g., Baltes \& Baltes, 1990), and socioemotional selectivity theory (SST; e.g., Carstensen et al., 1999). Developmental self-regulation (and its requisite mechanisms and well-being implications) has been a focal part of lifespan development study for over thirty years, with traditions that often hold foundational theories separate rather than considering them in concert (cf. Haase et al., 2013). This paper brings light to this issue, conducting a comprehensive operational integration of lifespan development theories. Our findings inform an integrative lifespan development theory, such as one considering the role of general regulatory ability and theoryspecific mechanisms, and their contributions to successful aging (see also Rauvola \& Rudolph, in press).

Research already published in this vein prompts further elaboration to be comprehensive, parsimonious, and useful for scholars, new and experienced alike. Theoretical work suggests distinctions and overlaps between developmental self-regulatory mechanisms (Greve \& Wentura, 2007; see also Boerner \& Jopp, 2007; Riediger \& Ebner, 2007), yet we lack comprehensive, empirical evidence of the degree to which these mechanisms do, indeed, a) meaningfully and differentially predict well-being outcomes, or b) diverge or converge, perhaps even with an 
underlying and integrative factor structure. Most research measures only one set of mechanisms in each study (cf. Freund \& Baltes, 2002) or has provided integration of only select mechanisms. Haase and colleagues (2013), for example, conducted an empirical integration focusing on AAC, MTLD, and SOC. In two studies, the validity and utility of a three-process, integrative model of lifespan development was tested. Comprised of goal engagement, goal disengagement, and metaregulation processes, this model was tested alongside potential age, process, and well-being relationships. Their two studies (one including SOC) provide support for this three-process model and evidenced well-being relationships in expected directions. Still, limitations are highlighted to address in future research, including the absence of theoretical constructs from SOC (loss-based selection) and SST, and the use of archival data, small sample sizes, and single time-point data collection.

The present work fills gaps in past work and furthers synthesis through two goals: first, to consider self-regulatory lifespan constructs in concert, evaluating distinctions and commonalities through confirmatory factor analysis; and second, to assess the predictive power of developmental self-regulation mechanisms for "successful aging"-relevant outcomes (i.e., subjective and psychological well-being). This first goal harkens back to groundbreaking work on intelligence from Spearman (1927), which revolutionized the way scholars viewed intelligence: instead of existing in a multitude of distinct forms, Spearman demonstrated that intelligence could be thought of in terms of $G$ (a cross-cutting, general factor of intellectual ability) and $S$ (group factor(s) of specific intellectual ability/ies). This was initially met with resistance (Burt, 1947), with many viewing this as a reductive exercise instead of the integrative, inclusive act that it was. Our work is inspired by Spearman's provocations, and we hope to urge the adoption of a similar model of developmental self-regulation. 
To this point, our second goal does not imply that developmental self-regulation mechanisms directly impact or propagate well-being; instead, it is through the adaptive use of these mechanisms, in concert, that developmental self-regulation occurs and, in turn, has wellbeing consequences. The present study's hypotheses (and findings) regarding the bifactor structure of developmental self-regulation (i.e., with general and specific components, as in Spearman's work), discussed later, will clarify this point. We next present an overview of the lifespan development perspective and its theoretical manifestations, focusing on conceptual similarities and differences.

\section{The Lifespan Development Approach}

Lifespan theories emphasize the dynamic and discontinuous nature of development. Specifically, development is construed as a) lifelong and b) multidirectional, c) defined by jointly occurring gains and losses as well as d) intraindividual plasticity, contextualized by e) historical-cultural conditions and f) interactions between developmental influences (i.e., agegraded, history-graded, and non-normative), and g) best considered from a multidisciplinary perspective (Baltes, 1987).

Self-regulatory mechanisms enable individuals to remain agents of their development across the lifespan, providing tools to navigate gains and losses and maintain well-being. Mechanisms from each lifespan development theory differ in name and focus, but they pertain to the recognition of life circumstances, the selection of appropriate goals, the optimal use of and/or acquisition of goal-relevant means, and the maximization of control and well-being through goal engagement strategies and revisions.

Overarching principles and considerations define this theoretical space, including the relevance of context, time, and orchestrational abilities that help "manage" strategic motivational 
processes (see online appendix Table 1 for how these components manifest in theory and measurement). Orchestration within temporal and social contexts translates into (mal)adaptive developmental self-regulation, which links particular mechanisms to well-being (dis)advantages. Lifespan research assumes, but does not typically test, the impact of mechanisms on developmental self-regulation; instead, it presents direct relationships between mechanisms and well-being outcomes, with implied links to developmental self-regulation as a more general entity. Relatedly, shared principles across theories of lifespan development (e.g., time and timing) are often presented in theoretical discussions but are omitted from empirical work. Through more integrative thinking about the structure of developmental self-regulation, and the joint consideration of the four theories that follow, this study is poised to help future research address such issues.

AAC. AAC (Brandtstädter \& Renner, 1990) explains individuals' efforts to maintain self-consistency (i.e., stability in self-concept; congruence between actual and desired states) with age through two processes: assimilative (i.e., via tenacious goal pursuit) and accommodative coping (i.e., via flexible goal adjustment). Assimilative coping involves active adjustments to one's circumstances, resources, and/or capacities to increase the chances of reaching one's desired state, while accommodative coping refers to "neutralization"-based strategies wherein individuals adjust their goals to fit their perceived capacity and situation (e.g., lowering one's aspiration level, revising goal attainment priorities). Coping strategy initiation depends on the perceived discrepancy between current and desired states, with larger discrepancies resulting in more coping behaviors.

AAC's focus on self- and situation-evaluation, monitoring, and planning involves temporal, contextual, and orchestrational components, in line with the principles noted earlier. 
AAC overlaps with MTLD in its consideration of affect in the coping process, and in its treatment of assimilative coping processes (i.e., akin to goal engagement) and accommodation (i.e., akin to goal disengagement). These points suggest room for integration, through strategy selection and use, and the central role of context. Still, AAC is unique in positioning coping behaviors as instrumental to self-consistency rather than to primary control maintenance and enhancement (as in MTLD), and it has goal process "feedback loops" (i.e., contrasting the linear nature of MTLD's action phase model). Both coping strategies are theoretically (via developmental self-regulation) and empirically linked to well-being (e.g., Heyl et al., 2007; Kubicek et al., 2011).

Hypothesis 1. Tenacious goal pursuit and flexible goal adjustment will be positively related to subjective and psychological well-being.

MTLD. MTLD (Heckhausen et al., 2010) explains how individuals exert and maintain control with age. MTLD strategies fall within primary and secondary control categories: primary control involves attempts to change the environment to align with one's needs and goals, whereas secondary control involves efforts, directed toward goal-relevant internal states and processes, to support primary control (i.e., avoid losses, maintain current levels, or expand capacity). Within these categories are selective and compensatory sub-processes: selective primary control involves resource investment (e.g., time, effort) into goal striving, whereas selective secondary control involves cognitive and motivational shifts to maintain goal commitment (e.g., self-affirmations). When internal resources are insufficient, compensatory primary control strategies are engaged by involving external resources in goal striving (e.g., technical aids, help from others). Whereas these three strategies are related to goal engagement, compensatory secondary control strategies are related to goal disengagement: when goal 
obstacles make goals unattainable or overly resource-intensive, compensatory secondary control strategies deactivate present goal(s) and free resources for attainable goals. Finally, a metaregulative process of "optimization" represents how individuals schedule and choose developmental goals optimally geared for success with respect to time, opportunities, and the balance of primary control costs and benefits.

Optimization attends to contextual components of control striving: namely, that adaptiveness is defined within a given (goal) context, and that primary control capacity across domains is the ultimate target of successful aging in MTLD (Heckhausen et al., 2010, p. 35). Optimization also plays a role in assessing "time constraints, and long-term consequences" of goal investments (Heckhausen et al., 2010, p. 37). This, combined with considerations of developmental deadlines and other temporal goal opportunity shifts, make apparent that time (i.e., perceived time and urgency), context, and orchestration are central to this perspective. MTLD's strategies parallel other theories' as well (e.g., assimilative and accommodative coping with goal engagement and disengagement). Heckhausen and colleagues (2010) also discuss selectivity and compensation, and SOC strategies (elective and loss-based selection, optimization, and compensation) that parallel goal (dis)engagement (Haase et al., 2013).

In the literature, goal engagement is linked to positive well-being, although goal disengagement manifests mixed relationships with well-being outcomes (e.g., Haase et al., 2008; Haase et al., 2012) through their impacts on developmental self-regulation. These relationships can be situation- and context-dependent, with goal disengagement translating into adaptive selfregulation in certain circumstances, but the tendency to disengage from goals (in the absence of goal reengagement) is understood to be maladaptive (see Haase et al., 2012, p. 1740, discussing an occupational transition). 
Hypothesis 2 . Selective primary and secondary control, and compensatory primary control, will be positively related to subjective and psychological well-being. Hypothesis 3. Compensatory secondary control will be negatively related to subjective and psychological well-being.

No specific hypotheses regarding optimization and well-being were made, as it is suggested that optimization has an indirect influence on well-being through other control strategies (as demonstrated by Haase et al., 2013) and developmental self-regulation, in turn.

SOC. SOC (Baltes \& Baltes, 1990) explains how individuals maintain functioning and well-being in the face of mismatched demands and resources (e.g., resulting from age-related losses) through strategy use. Selection entails processes of goal development, choice, and commitment and can be distinguished as elective or loss-based in nature: elective selection concerns "desired state" goal setting, whereas loss-based selection concerns "maintenance" goal setting (i.e., in response to goal-relevant resource loss). Optimization and compensation refer to processes of goal attainment, as they are devoted to goal-relevant means and resources (e.g., skills). Optimization refers to the acquisition and application of available goal-relevant means, and compensation refers to the acquisition and application of alternative means (e.g., when other goal-relevant means are no longer tenable).

These strategies clearly resemble those described in AAC and MTLD, including desired vs. current state appraisals and goal setting, and seeking out internal and external goal-relevant means to support goal engagement and attainment (Haase et al., 2013). SOC is often presented with a "coordinated orchestration" (Baltes et al., 2007, p. 574) element whereby individuals successfully age through active management of selective, optimizing, and compensatory processes. This parallels the orchestrational functions characteristic of other lifespan 
development theories. Moreover, the use of SOC strategies is contingent upon contextual and personal appraisals (e.g., of available resources), and Baltes and colleagues (2007) note one must "specify the context and the developmental space in which a given behavioral event is considered" (p. 594) before defining behaviors as selective, optimizing, or compensatory, or even as adaptive (i.e., for developmental self-regulation). Engagement in each SOC component is theoretically (via the broader orchestration of developmental self-regulation) and empirically related to well-being (e.g., Freund \& Baltes, 2002; Moghimi et al., 2017).

Hypothesis 4. Elective and loss-based selection, optimization, and compensation will be positively related to subjective and psychological well-being.

SST. SST (Carstensen et al., 1999) elaborates the mechanisms by which goals are prioritized, selected, and strived toward across the lifespan. SST focuses on time, suggesting individuals self-contextualize their position in life relative to the passage of time: with age, individuals adjust their perceptions of the relative expansive or restricted nature of time. Goals, by definition, imply future orientation, and they are adjusted to "fit" one's general or domainspecific time horizon (i.e., in line with the goal domain, e.g., personal vs. occupational goals). This time horizon is an individual's future time perspective (FTP) and ranges from open-ended to constrained. More open-ended FTP is construed as an adaptive, motivating force across the lifespan, supporting the choice of well-being-enhancing goals (i.e., functioning through adaptive self-regulation). FTP is considered to have three dimensions: focus on opportunities, focus on limitations, and perceived remaining time (e.g., Rohr et al., 2017). Whereas focus on opportunities refers to perceptions of one's potential for new experiences and goal-setting and striving, focus on limitations refers to perceptions of constraints and limiting factors in one's remaining life. Finally, perceived remaining time refers to the amount of time one believes that 
they have left in life. Perceptions of greater opportunities and remaining time relative to limitations in one's remaining life (i.e., open-ended FTP) are favorable in terms of well-being (through adaptive developmental self-regulation), which past research supports (e.g., Brothers et al., 2016; Henry et al., 2017).

SST addresses similar questions about context, time, and orchestration in lifespan development as do the aforementioned theories, and it does so through a self-regulatory component (FTP) that is at once sparingly represented in other theories' measurement scales but heavily discussed and implied as a component of the other theories' postulates and processes. FTP presents a way of understanding the self-contextualization of regulatory decision-making, and SST's focus on social and temporal elements of developmental contexts makes it complementary to AAC, MTLD, and SOC (as noted in past theoretical and empirical work: e.g., AAC \& SST: Lang \& Damm, 2017; MTLD \& SST: Kooij \& Kanfer, 2019; SOC \& SST: Baltes \& Carstensen, 2003; Rudolph et al., 2018; Zacher \& Frese, 2011). SST's components are selfregulatory in their own right and serve as a potential "answer" to questions of time, context, and orchestration across the lifespan.

Indeed, while SST can be applied in specific goal selection scenarios (e.g., the relative prioritization of socioemotional and instrumental goals), its core construct, FTP, serves as a broadly applicable time-based developmental self-regulatory mechanism with implications for both goal selection and striving across domains. How individuals self-contextualize (i.e., relative to their social and temporal context) falls squarely within the scope of developmental selfregulation, as individuals' understanding of their circumstances and goal systems are a key component of goal (dis)engagement processes and goal-relevant resource acquisition and use (see Rauvola \& Rudolph, in press). Moreover, FTP is relevant regardless of goal content: goals 
are challenging to categorize as purely "socioemotional" or "instrumental," as, from a lifespan perspective, goals are selected, strived for, and imbued with value within an inherently social environment. That exact environment, in turn, shapes and is shaped by or drawn upon in goal striving. Therefore, how can we fully distinguish goals of relevance to emotions and the social world from those that are not?

Including SST in this integration helps account for critical temporal, evaluative, and monitoring components of developmental self-regulation across life domains and goal processes. Such components are too often omitted from the study of time-bound motivational processes in the lifespan literature.

Hypothesis 5. Focus on opportunities and perceived remaining time will be positively related to subjective and psychological well-being.

Hypothesis 6. Focus on limitations will be negatively related to subjective and psychological well-being.

Importantly, open-ended FTP is not necessarily adaptive across the entire lifespan. Just as temporal and contextual perceptions are central to goal selection and striving in AAC, MTLD, and SOC, realistic "matching" between time perceptions and limitations/opportunities is central to developmental self-regulation adaptiveness and well-being in SST. Here, again, is where integrating these four theories is apropos.

Integrating AAC, MTLD, SOC, and SST. Time, context, and orchestration span these theories, but "where" should they live in an integrative theory of lifespan development? Relatedly, how do these components of developmental self-regulation manifest in individuals? We can move toward answers by systematically testing possible factor structures of developmental self-regulation (and relationships with well-being therein), while considering both 
time- and orchestration-based mechanisms (e.g., optimization, FTP) alongside strategies (e.g., tenacious goal pursuit, flexible goal adjustment).

In light of conceptual and theoretical overlap in this literature, it was hypothesized that a bifactor model would emerge (see Figure 1), such that one common factor accounted for a portion of variance in each of the four theories' constructs and second-order, "group" factors accounted for the distinct variance presented by each theory's constructs (i.e., variance not accounted for by the common factor).

Hypothesis 7. A bifactor model will be observed, with one common factor accounting for shared variance across the four theories' constructs and second-order factors accounting for distinct theoretical scale variance.

This common factor could be representative of a general developmental self-regulatory ability (akin to Spearman's $G$ ) which individuals leverage in appraising themselves and their (temporal and social) context, and in selecting appropriate strategies to manage their lives and maintain well-being. The group factors, conversely, would represent theory-specific regulatory mechanisms (akin to Spearman's $S$ ) relevant to successful aging. A conceptualization of this nature helps to align and represent the full continuum of "successful aging" processes assumed in lifespan development theories: specifically, the serial linkages between specific mechanisms, developmental self-regulation, and ultimately, well-being. In reality, the well-being hypotheses presented earlier imply the presence of adaptive self-regulation as a "bridge" between motivational mechanisms and well-being, and the theoretical and empirical recognition of both specific (i.e., particular mechanism-related abilities) and overarching (i.e., general developmental self-regulatory ability) components in this literature would propel us closer to the codified study of both distal and proximal self-regulatory influences on well-being, respectively. 
As Baltes and Baltes (1990) suggest, "whether in the long run the concept of successful aging will remain a scientifically viable topic is perhaps less significant than its power in identifying and organizing questions and research directions that reflect the current dynamics of the field" (p. 4). Now, thirty years on, it is not only clear that successful aging has remained a scientifically viable topic, but also that the current dynamics of the field demand integration.

\section{Methods}

Study hypotheses and methods were pre-registered through the Open Science Framework to ensure transparency regarding hypothesis testing and analyses (pre-registration available via https://osf.io/uwn3m; online appendix (OA), datasets, and code files to reproduce the analyses presented here available via https://osf.io/9t5za/). This study received IRB review and approval before being conducted, meeting ethical guidelines and U.S. legal requirements. Informed consent was obtained from all individual participants included in the study.

\section{Procedure}

Participants were invited to participate in the survey at two times, two weeks apart. At each time, participants completed demographic information and a scale battery including means to assure attentive responding.

\section{Sampling \& Participants}

A survey panel management company was used for data collection to obtain an age representative, complete panel sample. After applying exclusion criteria (i.e., attention check failure, multiple survey attempts, impossible age values), 1091 participants completed the Time 1 survey, and of these, 506 participants also completed the Time 2 survey before participant recontact ceased. Participants were compensated approximately $\$ 2.50$ per completed survey. The sample had an average age of $43.64(\mathrm{SD}=13.27$; range 18-74) and were mainly female gender- 
identifying (69.17\%). A target sample size of 500 participants was determined and pre-registered a priori (see OA).

\section{Materials}

In addition to collecting demographic information, established scales were used to measure each of the study constructs (see OA), and to estimate method variance: a) Brandtstädter and Renner's (1990) TEN and FLEX scales, omitting reverse-coded items identified as problematic in past validation (e.g., Henselmans et al., 2011); b) items from Heckhausen and colleagues' (1998) Optimization of Primary and Secondary Control Scales; c) SOC-consistent items from Baltes and colleagues (1999; i.e., not including distractor or SOC-inconsistent items); d) Carstensen and Lang's (1996) Future Time Perspective Scale; e) Hays and colleagues' (1989) Socially Desirable Response Set Measure; f) Ryff’s (1989) Scales of Psychological Well-Being (short-form); and g) Diener's Satisfaction with Life Scale (Diener et al., 1985) and Scale of Positive and Negative Experience (Diener et al., 2009).

\section{Results}

Analyses were conducted using R (R Core Team, 2018). Descriptive statistics and correlations, along with descriptions of analytic procedures and additional tables, are in our OA. Due to non-normality, a robust maximum likelihood estimator was used for all models (Satorra \& Bentler, 2001).

Measurement model analyses. After establishing measurement invariance and assessing the developmental self-regulation scales' dimensional structures (see Tables 9-11), the fit of the hypothesized bifactor structure and alternative models was evaluated. Results were assessed using pre-registered "cut-off” values for model fit (i.e., SRMR <.08, CFI > .95, TLI > .95, RMSEA <.08). 
A bifactor model, with four latent group factors corresponding to the four lifespan development scales and one general factor of developmental self-regulation, was fit to the data and compared to five other models: a) an oblique model (i.e., four factors, one corresponding to each theory, allowed to correlate); b) an orthogonal model (i.e., same four factors, not allowed to correlate); c) an oblique model of goal engagement and disengagement as in Haase and colleagues' (2013) work (i.e., goal engagement, goal disengagement, and higher-order metaregulative factors with AAC, MTLD, and SOC); d) an oblique model with goal choice and goal striving factors; and finally e) a higher-order factor model with first-order factors representing each lifespan theory and associated constructs, and a second-order factor upon which the first-order factors loaded. These models align with different perspectives on possible developmental self-regulatory structures (e.g., oblique and orthogonal models consider developmental self-regulatory processes to be theory-specific).

The hypothesized bifactor model fit the data best (see Table 1; see Figure 1). AIC values corroborated this relative fit, with the bifactor model having the second lowest observed AIC value (the lowest belonging to a model with the fewest estimated parameters). Coefficient omega hierarchical was calculated to assess the reliability of the general factor (Rodriguez et al., 2016). The resulting coefficient omega was 0.67 , suggesting that $67 \%$ of total score variance can be attributed to individual variation on the general factor. Compared to the total omega coefficient for the model (0.71), the general factor is quite high, accounting for nearly all (i.e., 94.40\%) of the reliable observed variance in scores. Additionally, the bifactor model was found to replicate in a separate hold out cross-sectional sample $(N=585$; i.e., participants who completed only the Time 1 survey; see Table 2 and OA for more details).

[Insert Tables 1 and 2, and Figure 1, about here] 
Structural model analyses. Next, a structural bifactor model in which the general factor was used to predict variance in well-being outcomes was specified. The structural model included the general factor from the retained bifactor model as an exogenous variable (with corresponding construct scores as observed indicators) predicting psychological (i.e., autonomy, personal growth, environmental mastery, positive relations, purpose in life, self-acceptance) and subjective (i.e., satisfaction with life, positive and negative emotions) well-being as endogenous variables; this model fit the data adequately.

In the regressions of well-being variables onto the general developmental self-regulation factor, all partial regression coefficients were positive and significant (i.e., developmental selfregulation at Time 1 positively and significantly predicted psychological and subjective wellbeing at Time 2; see Table 3). Additionally, the well-being variance explained by the specified regression models exceeded $10 \%$ for all except two well-being variables (i.e., autonomy, purpose in life). The incremental predictive validity of the general factor over-and-above the scalespecific group factors was quite high, indicated by low $\Delta \mathrm{R}^{2}$ values when comparing models including the general factor with models including the general factor and scale-specific group factors (e.g., $\Delta \mathrm{R}^{2}=<.001$; see Table 4).

[Insert Tables 3 and 4 about here]

Sensitivity analyses. Four sensitivity analyses were conducted to determine whether observed relationships differed when a) including respondents excluded for attention check failure, b) testing structural or c) measurement models with shorter versions of subjective wellbeing scales, and d) including social desirability as a possible source of method variance (Williams \& McGonagle, 2016; see OA Tables 14-18). Broadly, the results suggest our findings are robust to analytic changes and unbiased by social desirability. The latter analyses specifically 
tested the degree to which common method variance might substantively impact observed factor structures. Common method variance is generally defined as a spurious but systematic form of variance that is attributable to one's measurement method (e.g., self-report surveys) rather than to the constructs being measured. Using Williams and McGonagle's (2016) method, we tested models (i.e., varying in their constraints and inclusion of social desirability) iteratively and found no evidence to suggest that social desirability, and thereby common method variance, impacted either the factor structures of developmental self-regulation or of well-being outcomes. Details of these model specifications and results can be found in our OA. In sum, however, there was no evidence to suggest that social desirability substantively impacts the observed factor structures of developmental self-regulation or well-being constructs. Based on these findings, we are confident that common method variance is not an appreciable concern in the present study.

\section{Discussion}

This study operationally integrates the developmental self-regulation literature and explores relationships between developmental self-regulation and well-being at multiple "levels" (i.e., individual constructs, general factor). Our bifactor model fit the data best when compared with alternative, theoretically viable models, and the general factor accounted for over $90 \%$ of observed variance. These findings replicated in a holdout sample (see Table 2 and OA), were robust to analytic changes, and unbiased by social desirability. Overall, all hypotheses (save for Hypothesis 3) were supported. The hypothesized bifactor model's superior fit informs our theoretical understanding of developmental self-regulation as a unified entity, orchestrated in a temporal and social context, and the relevance of considering a diverse set of both parallel and divergent mechanisms to this end. 
This investigation suggests the presence of theory-specific explanatory power and a cross-cutting developmental self-regulation ability. In the tradition of Spearman's $G$, we refer to this general factor of developmental self-regulation as " $D$." $D$ represents the way individuals appraise themselves and their context (e.g., with respect to goal-relevant social and temporal factors) and select situation-congruent strategies that result in well-being advantages, through adaptive self-regulation. This integration should provide direction for scholars new to the field, whether in recognizing overlaps and differences across lifespan development theories, guiding the selection of theoretical mechanisms to study, or in the service of theory-focused research (e.g., studying mechanism-developmental self-regulation-well-being linkages and the role of context, time, and orchestration).

\section{Limitations}

This study was designed to anticipate method variance issues through temporally separating predictor and outcome variables (Podsakoff et al., 2003); moreover, Williams and McGonagle's (2016) procedure confirmed that social desirability did not bias the observed results. Future research should explore other possible sources of method variance (e.g., affectivity, item valence). Additionally, the shortened scales used may not fully represent each construct's content domain. Care was taken to balance content coverage, validity, and length, but theoretical components may have been underrepresented. Future research could test the generalizability of the bifactor model to data from full versions of these scales. Consideration of different time-based mechanisms in addition to SST's FTP may be beneficial as well, broadening the temporal aspects captured in developmental self-regulation studies.

The methodology used herein should be taken into consideration when interpreting our results, as caution is warranted regarding our findings' generalizability to other developmental 
self-regulation measurement forms, as well as the possibility that findings are (at least in part) attributable to item overlap or positive self-report bias. Although care was taken to "rule out" method variance, these other sources of method variance could be avoided with the use of alternative measurement methods. Future studies should consider investigating other forms of common method variance, either through direct measurement (e.g., assessing other biases that might systematically impact response patterns) or through study designs to mitigate the risk of common method issues. Moreover, our results should be viewed with some degree of caution in light of the possible influence of non-social desirability-based common method variance thereon.

Another related limitation of the present study is its reliance on self-report measures, which should be addressed in future work (e.g., Gerpott et al., 2020). Specifically, there are observational, behavioral, and experimental approaches (e.g., Fung et al., 1999) related to the constructs considered herein, and future work should use these to assess the degree to which the present findings conceptually replicate. Because the mechanisms studied here are largely selfreflexive, self-report was the best approach for this integration attempt. Future work should consider using other methods to study these phenomena (e.g., how do self- and other-reports align or diverge, how do observational or behavioral measures influence or inform our understanding of social and temporal contexts, "adaptiveness", and "orchestration" in developmental self-regulation?).

\section{Future Research and Theory}

Additional future research directions are apparent; most notably, research should consider the relationships between specific developmental self-regulatory mechanisms, developmental self-regulation, and well-being outcomes. There is a dearth of studies considering the full scope of this theoretical space, especially using diverse methods to assess the translation of self- 
reported behaviors into actions, and taking into account context, time, and orchestration to this end. Relatedly, greater attention to the age-defined and -graded nature of developmental selfregulation is needed. Although we focused on holistic integration, research is needed that considers how age (and other factors) shape the adaptivity of particular mechanisms and their contributions to developmental self-regulation across the lifespan and, more distally, well-being, stability, and change. The implied contextual adaptivity of developmental self-regulatory efforts should be investigated in future work, particularly from the bifactor perspective proffered herein. For example, work could consider age- or other context-based contingencies that affect the utility of certain self-regulatory practices, in addition to research that broadly explores how and when individuals "age successfully" through their personal configurations of developmental selfregulation. The present study took a first step in this direction by focusing on what constitutes the structure of currently studied and measured developmental self-regulatory constructs.

Also to this point, the purpose of this study was not to recommend singular thinking in lifespan development. Instead, each theory of lifespan development considered in this work has value (as supported by the presence of both common and theory-specific factors), and this should be recognized in theoretical integration. Provided additional support for the bifactor model, theorists should account for $D$ in their models and identify the mechanisms through which this ability is cultivated or constrained. This study should also spur theoretical work on the temporal nature of developmental self-regulation, given SST's role in the bifactor model. Time is integral to motivation and lifespan development theories, and past work has proposed that time perceptions may serve an orchestrational function in an integrated model of developmental selfregulation (e.g., Rauvola \& Rudolph, in press; Rudolph, 2016). Generally, theoretical integration efforts should address specific areas of convergence (e.g., time, context, orchestration; 
overlapping strategies) and divergence (e.g., adaptiveness criteria, temporal ordering) noted herein.

Regarding the role of time, the present study makes apparent that SST is relevant to consider in integrative developmental self-regulation work, not only despite but perhaps because of the diversity of mechanisms it brings to the fore. From a conceptual standpoint, SST incorporates situational evaluation and monitoring as an aspect of developmental self-regulation (Rauvola \& Rudolph, in press): specifically, FTP serves as a key mechanism that interacts with goal (dis)engagement and resource acquisition and use as individuals work to "age successfully." Although some could argue (much as was in Spearman's time) that the approach taken herein is overly data-driven and reductive, our work's basis in theory, and its use of factor analysis as a meaningful research tool for testing theoretical propositions spanning the four theories of lifespan development, diminishes this concern (e.g., Vincent, 1953). Our inability to replicate Haase and colleagues' (2013) model as best-fitting could be due to a number of different factors, including methodological (e.g., sampling, measurement differences), statistical (e.g., differing approaches to parceled indicators; see Bandalos, 2002) or theoretical reasons (e.g., greater coverage of the developmental self-regulatory domain through representation of all four theories). Based on our expected and observed findings, we have most confidence in the latter explanation: our results support the representativeness of a bifactor approach to developmental self-regulation phenomena. It is our hope that the integrative theoretical discussion and empirical evidence presented herein supports continued synthesis work from both new and experienced scholars. 


\section{Conflict of Interest Statement}

On behalf of all authors, the corresponding author states that there is no conflict of interest. 


\section{References}

Baltes, M. M., \& Carstensen, L. L. (2003). The process of successful aging: Selection, optimization, and compensation. In U. M. Staudinger \& U. Lindenberger (Eds.), Understanding human development (pp. 81-104). doi:10.1007/978-1-4615-0357-6_5

Baltes, P. B. (1987). Theoretical propositions of life-span developmental psychology: On the dynamics between growth and decline. Developmental Psychology, 23, 611-626. doi:10.1037/0012-1649.23.5.611

Baltes, P. B., \& Baltes, M. M. (1990). Psychological perspectives on successful aging: The model of selective optimization with compensation. In P. B. Baltes \& M. M. Baltes (Eds.), Successful aging: Perspectives from the behavioral sciences (pp. 1-34). New York: Cambridge University Press.

Baltes, P. B., Baltes, M. M., Freund, A. M., \& Lang, F. (1999). The measurement of selection, optimization, and compensation (SOC) by self report. Berlin, Germany: Max Planck Institute for Human Development.

Baltes, P. B., Lindenberger, U., \& Staudinger, U. M. (2007). Life span theory in developmental psychology. In W. Damon \& R. M. Lerner (Eds.), Handbook of child psychology (pp. 569-664). doi:10.1002/9780470147658.chpsy0111

Bandalos, D. L. (2002). The effects of item parceling on goodness-of-fit and parameter estimate bias in structural equation modeling. Structural Equation Modeling, 9, 78-102. doi:10.1207/s15328007sem0901_5

Boerner, K., \& Jopp, D. (2007). Improvement/maintenance and reorientation as central features 
of coping with major life change and loss: Contributions of three life-span theories. Human Development, 50, 171-195. doi:10.1159/000103358

Brandtstädter, J., \& Renner, G. (1990). Tenacious goal pursuit and flexible goal adjustment: Explication and age-related analysis of assimilative and accommodative strategies of coping. Psychology and Aging, 5, 58-67. doi:10.1037/0882-7974.5.1.58

Brothers, A., Gabrian, M., Wahl, H.-W., \& Diehl, M. (2016). Future time perspective and awareness of age-related change: Examining their role in predicting psychological wellbeing. Psychology and Aging, 31, 605-617. doi:10.1037/pag0000101

Burt, C. (1947). (1) Some recent work in factorial analysis and a retrospect. (2) The factorial analysis of human ability. British Journal of Educational Psychology, 17, 40-48. doi:10.1111/j.2044-8279.1947.tb02207.x

Carstensen, L. L., Isaacowitz, D. M., \& Charles, S. T. (1999). Taking time seriously: A theory of socioemotional selectivity. American Psychologist, 54, 165-181. doi:10.1037/0003066x.54.3.165

Carstensen, L. L., \& Lang, F. R. (1996). Future time perspective scale. Stanford University, Stanford, CA.

Diener, E., Emmons, R. A., Larsen, R. J., \& Griffin, S. (1985). The Satisfaction with Life Scale. Journal of Personality Assessment, 49, 71-75. doi:10.1207/s15327752jpa4901_13

Diener, E., Wirtz, D., Biswas-Diener, R., Tov, W., Kim-Prieto, C., Choi, D., \& Oishi, S. (2009). New measures of well-being: Flourishing and positive and negative feelings. Social Indicators Research, 39, 247-266. doi:10.1007/978-90-481-2354-4_12

Freund, A. M., \& Baltes, P. B. (2002). Life-management strategies of selection, optimization and 
compensation: Measurement by self-report and construct validity. Journal of Personality and Social Psychology, 82, 642-662. doi:10.1037/0022-3514.82.4.642

Fung, H. H., Carstensen, L. L., \& Lutz, A. M. (1999). Influence of time on social preferences: Implications for life-span development. Psychology and Aging, 14, 595-604. doi:10.1037/0882-7974.14.4.595

Gerpott, F. H., Lehmann-Willenbrock, N., \& Scheibe, S. (2020). Is work and aging research a science of questionnaires? Moving the field forward by considering perceived versus actual behaviors. Work, Aging and Retirement, 6, 65-70. doi:10.1093/workar/waaa002

Greve, W., \& Wentura, D. (2007). Personal and subpersonal regulation of human development: Beyond complementary categories. Human Development, 50, 201-207. doi:10.1159/000103360

Haase, C. M., Heckhausen, J., \& Köller, O. (2008). Goal engagement during the school-work transition: Beneficial for all, particularly for girls. Journal of Research on Adolescence, 18, 671-698. doi:10.1111/j.1532-7795.2008.00576.x

Haase, C. M., Heckhausen, J., \& Silbereisen, R. K. (2012). The interplay of occupational motivation and well-being during the transition from university to work. Developmental Psychology, 48, 1739-1751. doi:10.1037/a0026641

Haase, C. M., Heckhausen, J., \& Wrosch, C. (2013). Developmental regulation across the life span: Toward a new synthesis. Developmental Psychology, 49, 964-972. doi:10.1037/a0029231

Hays, R. D., Hayashi, T., \& Stewart, A. L. (1989). A five-item measure of socially desirable response set. Educational and Psychological Measurement, 49, 629-636. doi:10.1177/001316448904900315 
Heckhausen, J., Schulz, R., \& Wrosch, C. (1998). Developmental regulation in adulthood: Optimization in primary and secondary control-A multiscale questionnaire (OPSScales). Berlin, Germany: Max Planck Institute for Human Development.

Heckhausen, J., Wrosch, C., \& Schulz, R. (2010). A motivational theory of life-span development. Psychological Review, 117, 32-60. doi:10.1037/a0017668

Henry, H., Zacher, H., \& Desmette, D. (2017). Future time perspective in the work context: A systematic review of quantitative studies. Frontiers in Psychology, 8, 413. doi:10.3389/fpsyg.2017.00413

Henselmans, I., Fleer, J., van Sonderen, E., Smink, A., Sanderman, R., \& Ranchor, A. V. (2011). The tenacious goal pursuit and flexible goal adjustment scales: A validation study. Psychology and Aging, 26, 174-180. doi:10.1037/a0021536

Heyl, V., Wahl, H.-W., \& Mollenkopf, H. (2007). Affective well-being in old age: The role of tenacious goal pursuit and flexible goal adjustment. European Psychologist, 12, 119-129. doi:10.1027/1016-9040.12.2.119

Kooij, D. T., \& Kanfer, R. (2019). Lifespan perspectives on work motivation. In B. B. Baltes, C. W. Rudolph, \& H. Zacher (Eds.), Work across the lifespan (pp. 475-493). doi:10.1016/b978-0-12-812756-8.00020-7

Kubicek, B., Korunka, C., Raymo, J. M., \& Hoonakker, P. (2011). Psychological well-being in retirement: The effects of personal and gendered contextual resources. Journal of Occupational Health Psychology, 16, 230-246. doi:10.1037/a0022334

Lang, F. R., \& Damm, F. (2017). Perceiving future time across adulthood. In G. Oettingen, A. T. Sevincer, \& P. M. Gollwitzer (Eds.), The psychology of thinking about the future (pp. 310-331). New York, NY, US: Guilford. 
Moghimi, D., Zacher, H., Scheibe, S., \& Van Yperen, N. W. (2017). The selection, optimization, and compensation model in the work context: A systematic review and meta-analysis of two decades of research. Journal of Organizational Behavior, 38, 247-275. doi:10.1002/job.2108

Podsakoff, P. M., MacKenzie, S. B., Lee, J.-Y., \& Podsakoff, N. P. (2003). Common method biases in behavioral research: A critical review of the literature and recommended remedies. Journal of Applied Psychology, 88, 879-903. doi:10.1037/0021-9010.88.5.879

Rauvola, R. S. \& Rudolph, C. W. (2022, In Press). Integrating lifespan development theories: Implications for the study of age(ing) and work. In H. Zacher \& C.W. Rudolph (Eds.), Age and work: Advances in theory, methods, and practice. Routledge.

R Core Team (2018). $R$ : A language and environment for statistical computing. R Foundation for Statistical Computing, Vienna, Austria. URL https://www.R-project.org/

Riediger, M., \& Ebner, N. C. (2007). A broader perspective on three lifespan theories: Comment on Boerner and Jopp. Human Development, 50, 196-200. doi:10.1159/000103359

Rodriguez, A., Reise, S. P., \& Haviland, M. G. (2016). Evaluating bifactor models: Calculating and interpreting statistical indices. Psychological Methods, 21, 137-150. doi: $10.1037 /$ met0000045

Rohr, M. K., John, D. T., Fung, H. H., \& Lang, F. R. (2017). A three-component model of future time perspective across adulthood. Psychology and Aging, 32, 597-607. doi:10.1037/pag0000191

Rudolph, C. W. (2016). Lifespan developmental perspectives on working: A literature review of motivational theories. Work, Aging and Retirement, 2, 130-158. doi:10.1093/workar/waw012 
Rudolph, C. W., Kooij, D. T. A. M., Rauvola, R. S., \& Zacher, H. (2018). Occupational future time perspective: A meta-analysis of antecedents and outcomes. Journal of Organizational Behavior, 39, 229-248. doi:10.1002/job.2264

Ryff, C. D. (1989). Happiness is everything, or is it? Explorations on the meaning of psychological well-being. Journal of Personality and Social Psychology, 57, 1069-1081. doi:10.1037/0022-3514.57.6.1069

Satorra, A., \& Bentler, P. M. (2001). A scaled difference chi-square test statistic for moment structure analysis. Psychometrika, 66, 507-514. doi:10.1007/bf02296192

Spearman, C. (1927). The abilities of man: Their nature and measurement. London, UK: Macmillan.

Vincent, D. F. (1953). The origin and development of factor analysis. Journal of the Royal Statistical Society: Series C (Applied Statistics), 2, 107-117. doi:10.2307/2985729

Williams, L. J., \& McGonagle, A. K. (2016). Four research designs and a comprehensive analysis strategy for investigating common method variance with self-report measures using latent variables. Journal of Business and Psychology, 31, 339-359. doi:10.1007/s10869-015-9422-9

Zacher, H., \& Frese, M. (2011). Maintaining a focus on opportunities at work: The interplay between age, job complexity, and the use of selection, optimization, and compensation strategies. Journal of Organizational Behavior, 32, 291-318. doi:10.1002/job.683 
Table 1

Developmental Self-Regulation CFA Fit Indices in Time 1 Panel Sample $(N=506)$

\begin{tabular}{lcccccccc}
\hline \multirow{2}{*}{ Model } & $\begin{array}{c}\boldsymbol{\chi}^{2} \\
\text { Scaled }\end{array}$ & $\begin{array}{c}\boldsymbol{\chi}^{2} \text { Scaled } \\
\boldsymbol{p} \text {-value }\end{array}$ & $\begin{array}{c}\text { Robust } \\
\text { CFI }\end{array}$ & $\begin{array}{c}\text { Robust } \\
\text { TLI }\end{array}$ & $\begin{array}{c}\text { Robust } \\
\text { RMSEA }\end{array}$ & $\begin{array}{c}\text { Robust } \\
\text { RMSEA CI }\end{array}$ & \multirow{2}{*}{ SRMR } & \multirow{2}{*}{ AIC } \\
\hline \hline Orthogonal & 1287.35 & $<0.001$ & 0.65 & 0.58 & 0.20 & $0.19-0.21$ & 0.38 & 16212.66 \\
Choice/Striving & 646.57 & $<0.001$ & 0.84 & 0.81 & 0.13 & $0.12-0.14$ & 0.07 & 15398.70 \\
Goal Eng./Dis. & 333.13 & $<0.001$ & 0.89 & 0.86 & 0.13 & $0.11-0.14$ & 0.15 & 10367.03 \\
Oblique & 322.24 & $<0.001$ & 0.93 & 0.91 & 0.09 & $0.08-0.10$ & 0.05 & 15012.56 \\
Higher-Order & 321.37 & $<0.001$ & 0.93 & 0.92 & 0.09 & $0.08-0.10$ & 0.05 & 15008.56 \\
Bifactor & 279.38 & $<0.001$ & 0.94 & 0.92 & 0.09 & $0.08-0.10$ & 0.04 & 14974.77 \\
\hline \hline
\end{tabular}

Table 2

Developmental Self-Regulation CFA Fit Indices in Time 1 Hold Out Sample $(N=585)$

\begin{tabular}{lcccccccc}
\hline \hline \multirow{2}{*}{ Model } & $\begin{array}{c}\boldsymbol{\chi}^{2} \\
\text { Scaled }\end{array}$ & $\begin{array}{c}\boldsymbol{\chi}^{2} \text { Scaled } \\
\boldsymbol{p} \text {-value }\end{array}$ & $\begin{array}{c}\text { Robust } \\
\text { CFI }\end{array}$ & $\begin{array}{c}\text { Robust } \\
\text { TLI }\end{array}$ & $\begin{array}{c}\text { Robust } \\
\text { RMSEA }\end{array}$ & $\begin{array}{c}\text { Robust } \\
\text { RMSEA CI }\end{array}$ & SRMR & \multirow{2}{*}{ AIC } \\
\hline Orthogonal & 1438.42 & $<0.001$ & 0.64 & 0.57 & 0.19 & $0.19-0.20$ & 0.34 & 19052.41 \\
Choice/Striving & 837.00 & $<0.001$ & 0.80 & 0.76 & 0.14 & $0.13-0.15$ & 0.07 & 18334.80 \\
Goal Eng./Dis. & 389.74 & $<0.001$ & 0.87 & 0.84 & 0.13 & $0.12-0.14$ & 0.15 & 12304.70 \\
Oblique & 402.46 & $<0.001$ & 0.91 & 0.89 & 0.10 & $0.09-0.11$ & 0.06 & 17845.54 \\
Bifactor & 379.25 & $<0.001$ & 0.92 & 0.89 & 0.10 & $0.09-0.11$ & 0.05 & 17809.43 \\
\hline \hline
\end{tabular}


Table 3

Structural Model Coefficients and Variance Explained in Panel Sample $(N=506)$

\begin{tabular}{|c|c|c|c|c|c|c|}
\hline \multirow[t]{2}{*}{ Variable } & \multicolumn{2}{|c|}{$\begin{array}{c}\text { Unstandardized } \\
\text { Coefficients }\end{array}$} & \multirow{2}{*}{$\begin{array}{c}\text { Standardized } \\
\text { Coefficients } \\
\beta\end{array}$} & \multirow{2}{*}{$\begin{array}{c}z- \\
\text { values }\end{array}$} & \multirow{2}{*}{$\begin{array}{c}p- \\
\text { values }\end{array}$} & \multirow{2}{*}{$\begin{array}{c}R^{2} \\
\text { (\% variance } \\
\text { explained) }\end{array}$} \\
\hline & $b$ & SE & & & & \\
\hline Autonomy & .205 & .044 & .231 & 4.683 & $<0.001$ & $.053(5.3 \%)$ \\
\hline Environmental Mastery & .592 & .047 & .574 & 12.582 & $<0.001$ & $.329(32.9 \%)$ \\
\hline Personal Growth & .459 & .040 & .502 & 11.517 & $<0.001$ & $.252(25.2 \%)$ \\
\hline Positive Relations & .363 & .051 & .339 & 7.156 & $<0.001$ & $.115(11.5 \%)$ \\
\hline Purpose in Life & .283 & .051 & .287 & 5.567 & $<0.001$ & $.083(8.3 \%)$ \\
\hline Self-Acceptance & .540 & .054 & .482 & 9.912 & $<0.001$ & $.233(23.3 \%)$ \\
\hline Life Satisfaction & 4.187 & .335 & .547 & 12.512 & $<0.001$ & $.299(29.9 \%)$ \\
\hline Pos. \& Neg. Emotions & 4.798 & .405 & .558 & 11.834 & $<0.001$ & $.312(31.2 \%)$ \\
\hline
\end{tabular}


Table 4

Structural Model Coefficients and Variance Explained for Incremental Model Tests $(N=506)$

\begin{tabular}{|c|c|c|c|c|c|c|c|}
\hline \multirow{2}{*}{ Variable } & \multirow{2}{*}{$\begin{array}{c}\mathrm{D} \boldsymbol{R}^{2} \\
\text { (\% variance } \\
\text { explained) }\end{array}$} & \multicolumn{2}{|c|}{ D + MTLD } & \multicolumn{2}{|c|}{$\mathrm{D}+\mathrm{SOC}$} & \multicolumn{2}{|c|}{ D + FTP } \\
\hline & & $\begin{array}{c}R^{2} \\
\text { (\% variance } \\
\text { explained) }\end{array}$ & $\Delta R^{2}$ & $\begin{array}{c}R^{2} \\
\text { (\% variance } \\
\text { explained) }\end{array}$ & $\Delta R^{2}$ & $\begin{array}{c}R^{2} \\
\text { (\% variance } \\
\text { explained) }\end{array}$ & $\Delta R^{2}$ \\
\hline Autonomy & $.053(5.3 \%)$ & $.071(7.1 \%)$ & .018 & $.103(10.3 \%)$ & .050 & $.077(7.7 \%)$ & .024 \\
\hline $\begin{array}{l}\text { Environmental } \\
\text { Mastery }\end{array}$ & $.329(32.9 \%)$ & $.325(32.5 \%)$ & .004 & $.434(43.4 \%)$ & .105 & $.332(33.2 \%)$ & .003 \\
\hline Personal Growth & $.252(25.2 \%)$ & $.262(26.2 \%)$ & .010 & $.342(34.2 \%)$ & .090 & $.252(25.2 \%)$ & .000 \\
\hline Positive Relations & $.115(11.5 \%)$ & $.122(12.2 \%)$ & .007 & $.154(15.4 \%)$ & .039 & $.116(11.6 \%)$ & .001 \\
\hline Purpose in Life & $.083(8.3 \%)$ & $.124(12.4 \%)$ & .041 & $.177(17.7 \%)$ & .094 & $.082(8.2 \%)$ & .001 \\
\hline Self-Acceptance & $.233(23.3 \%)$ & $.233(23.3 \%)$ & .000 & $.326(32.6 \%)$ & .093 & $.264(26.4 \%)$ & .031 \\
\hline Life Satisfaction & $.299(29.9 \%)$ & $.342(34.2 \%)$ & .043 & $.319(31.9 \%)$ & .020 & $.370(37.0 \%)$ & .071 \\
\hline Pos. \& Neg. Emotions & $.312(31.2 \%)$ & $.337(33.7 \%)$ & .025 & $.364(36.4 \%)$ & .052 & $.314(31.4 \%)$ & .002 \\
\hline
\end{tabular}

Note. "D + MTLD" = model including the general factor, D, and the motivational theory of lifespan development group factor, "D + SOC" = model including the general factor, D, and the selection, optimization, and compensation group factor, "D + FTP" = model including the general factor, $\mathrm{D}$, and the future time perspective group factor 


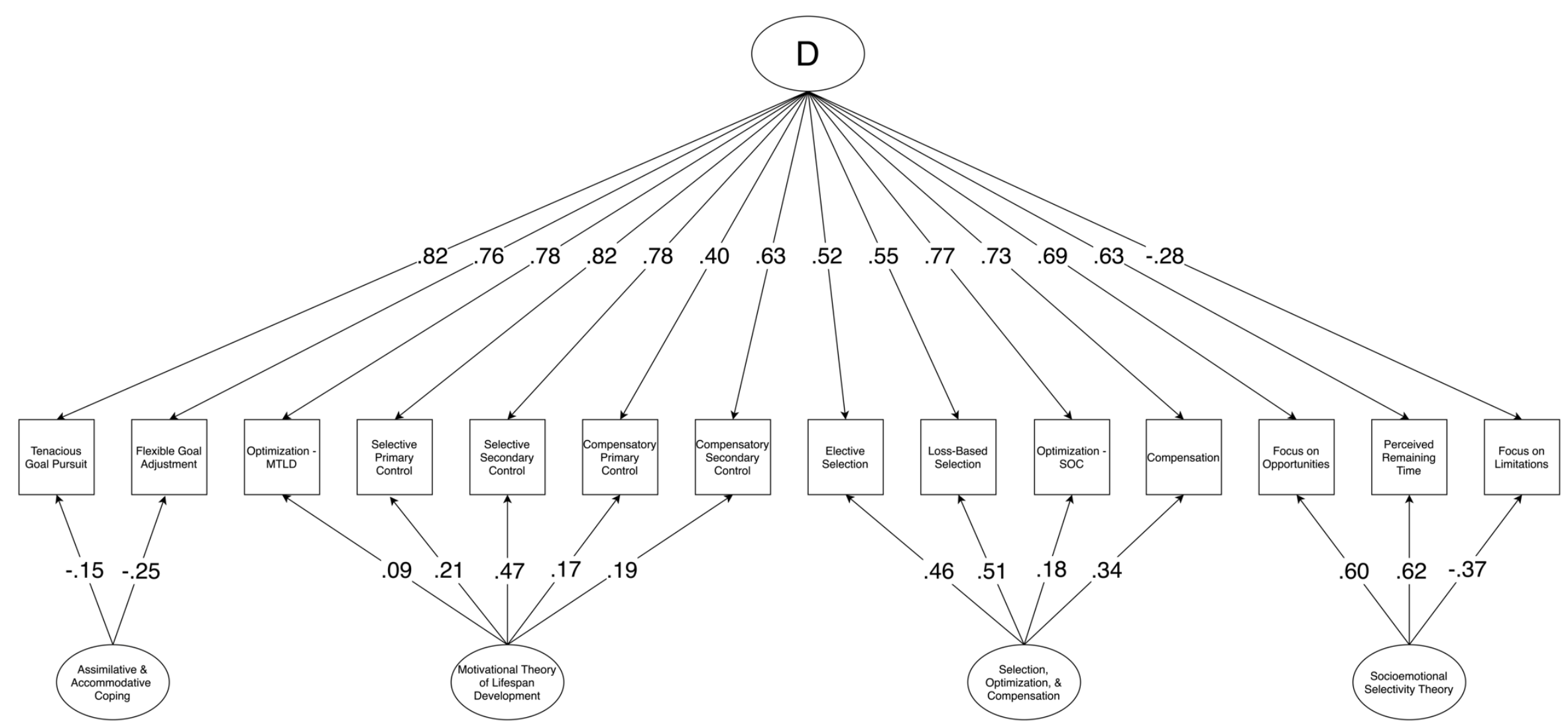

Figure 1. Bifactor model with standardized factor loadings in full panel sample $(N=506)$. Note. "D" = general factor of developmental self-regulation. 